\title{
Impact of Climate Change on the Global Environment and Associated Human Health
}

\author{
Zhiying Shi \\ Jiangsu Normal University, Xuzhou, China \\ Email: 958697204@qq.com
}

How to cite this paper: Shi, Z.Y. (2018) Impact of Climate Change on the Global Environment and Associated Human Health. Open Access Library Journal, 5: e4934.

https://doi.org/10.4236/oalib.1104934

Received: September 19, 2018

Accepted: October 16, 2018

Published: October 19, 2018

Copyright $\odot 2018$ by author and Open Access Library Inc.

This work is licensed under the Creative Commons Attribution International License (CC BY 4.0).

http://creativecommons.org/licenses/by/4.0/

\section{cc) (7) Open Access}

\begin{abstract}
As an important part of the natural environment on which human beings live, any change in climate will affect the natural ecosystem, social economy and human health. The impact of global climate change on human beings will be comprehensive, multi-scale and multi-layered. This paper mainly explores the research progress on the direct and indirect impacts of climate change on human health. It considers that the impacts of climate change on human health mainly include the following aspects: 1 ) heat wave effects; 2) extreme weather events; 3) insect-borne infectious disease; 4) hunger and malnutrition. In the end, the paper puts forward some suggestions about how to confront with the prevention of various diseases in the context of climate change. The impact of climate change on human health will be the focus of future research, which deserves much attention both at home and abroad.
\end{abstract}

\section{Subject Areas \\ Environmental Sciences}

\section{Keywords}

Climate Change, Human Health, Preventive Measures

\section{Introduction}

There is growing evidence that climate change has caused a range of direct and indirect effects on global and human health in the past few decades. Anthropogenic climate change since the 1970s is reported to have claimed over 150,000 lives and 5.5 million Disability Adjusted Life Years (DALYs) per year [1] [2]. Moreover, since the 20th century, the greenhouse gas emissions from human activities have risen sharply while the greenhouse effect has been exacerbated. The use of fossil fuels has brought tremendous progress to human society as well as 
brought about serious problems in the resources, environment and climate change. The global climate is experiencing a notable change characterized by warming, which has made a significant impact on the global ecosystem, socio-economy and human health and has constantly altered the exposure patterns of human risk to the outside world. Therefore, understanding the characteristics and trends of climate change is of great significance for exploring the impacts of climate change on human health, formulating relevant policies and adaptation strategies. The effects of climate change are tangible and demand actions [3] [4]. These actions can be mitigation, to prevent greenhouse gas (GHG) emissions or reduce their atmospheric concentration, or adaptation, to adjust to actual or expected climate and its effects [5]. With the global warming, environmental changes and frequent occurrence of extreme climate, frequency of occurrence and types of diseases and regions have changed obviously. Global climate change is the most dramatic and far-reaching change in the world, which has the most profound impact on human sustainable development. Intergovernmental Panel on Climate Change (IPCC), in its fifth assessment report, has confirmed that anthropogenic greenhouse gas emissions are the main causes of current climate change. Climate change is one of the biggest and menacing issues in our time and it has exerted a profound influence on the 21 st century.

In 2017, The 23rd Conference of Parties (COP23) to the United Nations Framework Convention on Climate Change (UNFCCC) has been held in Bonn from Nov. 6 to 17. The conference was held in the context of the imminent global climate action and the critical period of global climate negotiations, which amply illustrates that climate change is becoming a major international issue that profoundly affects global development in the twenty-first Century. Global warming may interfere with the weather patterns and ecological balance as well as affect the natural and biological systems of the region, resulting in a series of negative influences on human health in many aspects. Therefore, discussing the relationship between disease and natural climatic factors, and making feasible measures to prevent the possible occurrence of disease in view of different regions, different climatic conditions and sudden meteorological disasters, have very far-reaching significance to protect human health.

\section{The Impact of Climate Change on Human Health}

There are regional differences in the effects of climate change on human health, which depends on education, health care, public health defenses, the level of economic development and other related factors. Generally speaking, developing countries are at greater risks. Climate warming will bring some benefits for some residents in water shortage areas. For example, it may increase availability of water and reduce rates of death due to cold winter in mid and high latitudes. However, the influence of climate warming on nature and mankind will be mainly negative, and its negative effects can be divided into two aspects: direct influence and indirect influence. 


\subsection{Direct Impact}

\subsubsection{Heat Wave Effect}

In different meteorological conditions, the most sensitive impact on human health is the temperature. The direct effect of climate warming on human health is to increase the frequency or severity of heat wave attacks. Heat waves not only lead to fatalities due to heat strokes, but also increase the risks for residents to suffer from insomnia, fatigue, ill-nesses, etc. Comparing the average death rate of non-hot days ( $\operatorname{Tmax}<34 \pm \mathrm{C}$ ) with hot days (Tmax $>34 \pm \mathrm{C}$ ) and scorching days ( $\operatorname{Tmax}>36 \pm \mathrm{C}$ ), an increase is ob-served by $10.5 \%$ and $25 \%$, respectively [6]. As a matter of fact, heat waves have a lagging effect, which accompanies with high temperature make bacteria, viruses and parasites more active, damaging human immunity and resistance, which also leads to increased morbidity and mortality in heart, respiratory system and other heat-related diseases. The dangers of climate change for health are diverse and global. Plenty of high death rates are sensitive to climatic conditions and their occurrence and spread may be linked to climate change. The dangers of climate change for health are diverse and global. Plenty of high death rates are sensitive to climatic conditions and their occurrence and spread may be linked to climate change. The health effects of climate change are already evident in different ways. In fact, more people die of scorching heat than before. Numerous studies have shown that hot intensity and duration have a greater impact on mortality than instantaneous maximum temperature. Because of the urban heat island effect, high temperature in urban areas is not only high but also lasts for a long time. Thus, the impact of heat waves on human health is generally greater in cities than in suburbs and rural areas.

\subsubsection{Extreme Weather Event}

Climate warming may result in sea level rise and rainfall change in large areas. It can also cause frequent occurrences of extreme weather events such as droughts, floods, storms and forest fires, leading to the increase of mortality, morbidity, disability, incidence of infectious diseases and psychological abnormalities, and damage to public health infrastructure. In Bangladesh, 300,000 people were killed in the floods of the 1970s, threatening the homes of 46 million people.

\subsubsection{Insect-Borne Infectious Disease}

Another serious impact of climate warming on human health is the spread and resurgence of certain infectious diseases. Recent studies show that the increase of water temperature of coastal and river estuaries along with the associated mass propagation of seaweed that promotes the epidemic of cholera due to phytoplankton and zooplankton are the natural reservoirs of vibrio cholerae. The three trends of current insect-borne infectious diseases are as follows: new diseases are constantly being discovered, the existing endemic areas are expanding, and the frequency of epidemics are increasing. The continuous warming of the earth's climate has created favorable conditions for parasitism, reproduction and prop- 
agation of pathogens, expanding the extent and scope of prevalent, and thereby aggravating the harm to the population.

\subsection{Indirect Influence}

The indirect effects of global warming on human beings are mainly affected by infectious diseases. Global warming has widened the epidemic range of communicable diseases. More seriously, it can lead to the spread and recovery of certain communicable diseases. Furthermore, as temperature and humidity increase, climate warming will fortify the concentration of certain harmful substances in the air, such as fungal cells, pollen, and atmospheric particulate matter, which will also result in an increase incidence of allergic diseases such as hay fever, allergic asthma and other respiratory diseases in the population. Climate warming can indirectly affect human health through the influence of soil, plant photosynthesis and insect pests. In addition, the gases that mainly contain CFC in greenhouse gases have a greater destructive effect on the ozone layer, which leads to increased ultraviolet radiation in the sun, potentially increasing the incidence of skin cancer, cataracts and blindness. Climate change can also worsen air pollution and thus affect human health. For example, higher temperature would promote the generation of various secondary air pollutants, such as ozone and suspended particulates. Meantime, the incidence of allergies, heart and lung abnormalities and deaths caused by these air pollutants increased accordingly.

\section{Countermeasures to Mitigate the Impact of Climate Change on Human Health}

The challenges posed by climate change to human health are unavoidable. It is our common responsibility to protect the climate of earth, slow down the global warming and prevent it from deteriorating. To this end, the following measures should be taken:

\subsection{Raise Society's Concerns about the Relationship between Global Warming and Health}

It is time that strengthens publicity to the public and make the entire community aware of the health problems caused by global climate change. Through guiding people to adapt to climate change so as to protect their own health. The general public should enhance precaution consciousness of natural disasters caused by extreme weather. In daily life, people should actively learn scientific health knowledge, and develop good living habits, conducting social physical fitness exercises and enhancing physical fitness in order to reduce the risk of disease-causing factor. Besides that, calling on all people to raise their awareness on energy conservation and emission reduction and environmental protection. For example, increasing the use of bicycles and public transport to replace private cars, which will surely reduce greenhouse gas emissions and improve air quality. The whole society ought to attach importance to global warming and work to- 
gether to mitigate climate warming and ensure health by publicizing and educating people about the dangers of climate warming on human health as well as improving people's awareness of environmental protection.

\subsection{Vigorously Carry Out Research on the Relationship between Climate Change and Human Health}

Strengthening the study of complex pathways and mechanisms about the impact of global environmental change on human health and establishing relevant models to promote multidisciplinary comprehensive investigation and research.

\subsection{Promoting International Cooperation}

Climate warming is endangering human health. Various international cooperation and exchanges should be vigorously carried out, including government cooperation and non-governmental communication, reinforcing our ability to resist climate warming and benefit human health. Simultaneously, the establishment of a global environment-disease surveillance system is undoubtedly an effective measure to control and eliminate the impact of global climate change on human health.

\subsection{Attach Importance to the Formulation and Research of Relevant Policies}

All levels of governments and related departments should further formulate and improve the relevant policies and regulations. To fully implement the measures of carbon dioxide reduction and mitigate the harm of climate warming to human health from the source. Specifically, including two aspects: on the one hand, needing to enhance the effectiveness of power stations, industries, civilian energy and reduce fossil fuel consumption; On the other hand, it is essential to develop more clean and effective renewable energy, such as wind, waves, solar energy and so on. At the same time, prohibiting or reducing deforestation, maintaining species diversity and a good ecological environment are rather critical measures.

\section{Outlook}

To sum up, climate change will have many impacts on natural ecosystems, national economy and human health. Some of the impacts may be irreversible and catastrophic. Because the influence of climate change is very broad, we should gradually expand the scope of research in future studies and establish partnerships among countries. Apart from the above efforts, government agencies, intergovernmental and non-governmental organizations, industry and professional groups and local communities should give play to their respective expertise, trying their bests to carry out joint research. Namely, all relevant departments need to collaborate to find enough innovative and effective solutions to stabilize the climate and protect health. In the face of the global warming issue, we should 
speed up the public exchange platform for building global climate change and health risks as well as step up public preventive awareness for the sake of protecting human health.

\section{Conflicts of Interest}

The author declares no conflicts of interest regarding the publication of this paper.

\section{References}

[1] Patz, J.A., Campbell-Lendrum, D., Holloway, T. and Foley, J.A. (2005) Impact of Regional Climate Change on Human Health. Nature, 438, 310-317. https://doi.org/10.1038/nature04188

[2] Haines, A., Kovats, R.S., Campbell-Lendrum, D. and Corvalan, C. (2006) Climate Change and Human Health: Impacts, Vulnerability and Public Health. Public Health, 120, 585-596. https://doi.org/10.1016/j.puhe.2006.01.002

[3] Pielke, R., Prins, G., Rayner, S. and Sarewitz, D. (2007) Lifting the Taboo on Adaptation. Nature, 445, 597-598. https://doi.org/10.1038/445597a

[4] Klein, R.J.T. (2011) Adaptation to Climate Change. More than Technology. In: Linkov, I. and Bridges, T.S., Eds., Climate: Global Change and Local Adaptation. NATO Science for Peace and Security Series, Springer, Dordrecht, 157-168. https://doi.org/10.1007/978-94-007-1770-1_9

[5] Field, C.B., Barros, V.R., Mach, K.J., Mastrandrea, M.D., van Aalst, M., Adger, W.N., et al. (2014) Technical Summary. In: Field, C.B., Barros, V.R., Dokken, D.J., Mach, K.J., Mastrandrea, M.D., Bilir, T.E., et al., Eds., Climate Change 2014: Impacts, Adaptation and Vulnerability. Part A: Global and Sectoral Aspects. Contribution of Working Group II to the Fifth Assessment Report of the Intergovernmental Panel on Climate Change, Cambridge University Press, Cambridge and New York, 35-94.

[6] Tan, G.-R. (1994) Potential Impact of Global Warming on Human Mortality in Shanghai and Guangzhou, China. Acta Scientiae Circumstant, 14, 368-373. (In Chinese) 